\title{
Analysis of effects of psychological consultation in psychological health education of college students
}

\author{
Aimei Zhang \\ Zhengzhou Tourism College, Zhengzhou, 450046, China
}

Keywords: psychological consultation; psychological health education; college student

\begin{abstract}
Currently, college students in China have some problems in psychological health. Meanwhile, psychological health education also lags behind. Flexible application of psychological health consultation can promote psychological health education of college students and drive healthy development of college students. This paper will simply set forth effects of psychological consultation in psychological health education of college students.
\end{abstract}

\section{Introduction}

As quality-oriented education generalizes, moral education is a priority among priorities in college education. It is required to cultivate good psychological quality of college students, improve their psychological health level and drive development of psychological health education. These have become the key points of education. To enhance psychological health education of college students, it is required to comprehensively know psychological health status of college students, hold various psychological consultation activities, guide their psychological development, improve their psychological morality and lay foundation for future comprehensive development.

\section{Manifestations of psychological problems of college students}

Psychological consultation is a process of helping help seekers to solve psychological problems by professionals. In the process of psychological consultation, psychological consultants follow the principle of psychology to solve psychological problems of help seekers according to professional knowledge, professional methods and skills.

Currently, psychological problems of college students are mainly manifested in the following aspects: firstly, student's learning problem. College is a key period of development of students, but students often have insufficient learning motivation and no clear learning objective. Some students do no own good learning habits and learning anxiety exists generally. Secondly, college students as young people have very rich emotions. Emotional problems of college students mainly include the following: self-control ability is poor; their emotion is vulnerable; anti-pressure ability is weak; negative emotion prevails. Thirdly, self-psychological problema. Current college students generally have such psychological problems as self-interest, self-abasement, self-centeredness and lack of objective self-evaluation. Many students are indulged in self-appreciation and fail to comprehensive know themselves. Fourthly, interpersonal psychological problem. For college students, their contact objects include teachers, students, friends and parents, but many college students show the sense of conflict due to unsatisfactory major or unsatisfactory college. They even have behavioral biases during contact with friends with opposite sex. Thus, morality problem of college students can be easily triggered. Teachers and students lack the sense of trust and have obvious sense of trust. As mobile network popularizes, many students depend on various network chatting tools for communications such as QQ and WeChat. In such network environment lacking supervision constraining force, since students' moral self-discipline is poor, people become indifferent and even interpersonal communication obstacles appear. Fifthly, sexual psychological problem. Physical growth of college students continuously perfects with age, and secondary sex characteristic gradually become mature. Meanwhile, influenced by western thoughts, sex consciousness and sexual emotion of many students start to germinate. Students yearn for knowing more sexual knowledge, but meanwhile worry to be ridiculed due to the influences of traditional thought. 
Therefore, college students have many sex psychological health problems. Many students are even sensitive to sex psychology, like to talk about sex topics and take delight in spreading sex-related contents. Sixthly, employment psychological problem. For college students, the four-year learning aims to land an ideal job and give ply to their values. Various colleges care for students' problem of employment. This is also the critical selection for students. In the key link, students often show complex ambivalence, including excitement, tension and anxiety.

\section{Effects of psychological consultation in psychological health education of college students}

\section{To improve effectiveness of psychological health education of college students}

The practice of psychological health education of college students generates psychological consultation. In the middle and later period of the last century, since psychological consultation professionals cannot satisfy social demand, America raised psychological education reform of non-professional psychological consultation. Since the quantity of psychological consultation professionals is insufficient, many colleges considered cultivating some students to psychological consultation professionals through examinations in order to make up for insufficient psychological consultation professionals and meanwhile help other students solve psychological problems. Later, America, Japan and Canada studied such new psychological consultation mode. Since the new period, great reform has happened to Chinese society. The economic develops rapidly. World outlook, outlook on life and values of college students have enormous changes and present new features. Psychological health problems of college students increase gradually. All sectors of society pay high attention to this. According to the investigation of relevant departments, Chinese college students are generally faced with psychological problems such as learning, emotion, interpersonal communication and employment. It is hard to solve their psychological problems only through depending on current psychological health education. Psychological consultation must be applied to help students solve psychological problems. In recent years, peer psychological consultation is the latest psychological health education mode and can further enhance effectiveness of psychological health education of college students and let more students receive help. In traditional psychological consultation, consultation site and time are fixed, and the form is single. Such new psychological consultation mode is not limited by time and site. Colleges can select the students with high psychological quality to train them and let them become psychological consultants to serve classmates. Meanwhile, during carrying out psychological consultation, the forum, psychological health website and psychological consultation hotline can be created to solve psychological health problems of college students and enhance effectiveness of psychological health education of college students.

\section{To optimize network of psychological health education of college students}

At present, most colleges in china adopt three-level working system for psychological health education, i.e. college, school and student organization. In a sense, such working system works to some extent. In particular, psychological health education network at college and school levels are relatively perfect. Psychological health education leading group and psychological health education center are established, respectively. But, psychological health education at the kevel of student organization shows obvious insufficiency. In psychological health education of college students, students' initiative and subjectivity are not reflected really. As a new psychological health education mode, psychological consultation stresses people first and respect of people. People are equal and interdependent. In psychological consultation activities, consultants can lean and live with students jointly. If the distance between consultants and students is close, they can communicate frequently and conveniently. Students and consultants know each other well, so they can open their mind to exchange and mutually support. Psychological problems of college students form through long-term accumulation. These problems will certainly show in daily life and learning. Psychological consultants widely contact with students, can timely discover their abnormal behavior in daily life and study and help them solve psychological problems. In case of any psychological problem, college students can take the initiative to contact consultants to solve problems. This has important significance for psychological health of college students. In psychological consultation, peer 
psychological consultation can make college students with healthy psychology to help those with psychological problems to promote implementation of psychological health education of college students, timely find and solve problems and prevent adverse events in campus.

\section{Expand channels to gain social support}

Psychological consultation can provide college students with the services which school education cannot provide. In psychological consultation, students can solve various psychological problems by the experts and meanwhile gain more help and support through student consultants. In this way, the problems can be solved when teachers do not perceive them. According to data survey of relevant departments, when college students have psychological problems, $78 \%$ of them will tell their friends; $46 \%$ of them will tell their parents; $38 \%$ of them will tell their classmates; less than $4 \%$ of them will tell consultants. It thus can be seen that colleges must select specific techniques and methods according to psychological characteristics of college students when carrying out psychological health education. College students are in the puberty. When they encounter various psychological doubts, they tend to pour out them to the peers. This is because the peers know each other. During carrying out psychological consultation, peer psychological consultation activities carried out through the force of student organizations can better solve students' psychological problems and give students more social support. In essence, the help among students reflects friendship, emotion and lofty morality. It is because of such friendship that students can express their feelings with nay reservation, gain understanding of fiends and continuously deepen mutual feelings.

\section{Enhance team force of psychological health education of college students}

The Ministry of Education provides that the proportion of college psychological health education personnel and students should keep 1:500. However, according to actual survey data, this proportion is controlled within 1:10000. Besides, the number of psychological health education teachers in Chinese colleges is small, and the teaching team is single. There are basically full-time psychological health education teachers. There are few teachers with other knowledge structure. Although many colleges have set up psychological consultancy organizations, if the number of psychological education teachers cannot meet students' psychological consultation demand, psychological consultancy organizations cannot give play to the effects. Therefore, peer psychological consultation can well make up for the problem of insufficient psychological health education teachers and expand teaching team of psychological health education. Colleges can select the accommodating students with strong psychological quality, sense of responsibility from student backbones to train them and then let them participate in psychological consultation. Currently, psychological problems of college students show certain hierarchy, including common psychological confusion and serious mental disease. The psychological problems of most students mainly concentrate in daily study and life. Only a few students have serious psychological problems which must be solved by professional consultants. Most students just need non-professional psychological consultation personnel top guide them to solve problems. So, colleges can train a batch of non-professional psychological consultation personnel with the help of student organizations or student cadres to guide students to solve psychological problems. This can not just solve psychological problems of college students. The students as psychological consultation personnel can improve their ability and learn how to conduct themselves and communicate with others. Cui Rixiong (college psychology professor) once said the effect of a non-professional psychological consultant is not inferior to psychological consultation experts. This also shows the important effect of peer psychological consultation in psychological consultation. It can make up for insufficient psychological health education of college students and enhance teaching force of psychological health education.

\section{Skills to apply psychological consultation in psychological health education of college students}

Firstly, listen attentively. When college students seek psychological consultation, it is required to know their psychological health status through listening attentively. A qualified psychological consultant must be an excellent listener. Psychological consultants are required to observe facial 
expressions of help seekers, gain other important information apart from language and pay attention to eye contract with help seeks in the listening process. In this way, psychological consultants can see disappointment, panic and anxiety of help seekers. During communications, psychological consultants should apply various gestures and body languages to help help seekers to relax and express their support, trust and comfort of students' emotions and enhance language infection. Secondly, concentrate. In the process of psychological consultation, psychological consultants should fully concentrate on the communication with help seekers, carefully listen to students, comprehensively observe their tiny responses and express understanding of and attention to students through language or movements at the key places so as to let students feel they are valued. Besides, psychological consultants should apply various phrases to express they are listening, such as "er and yes”. Psychological consultation aims to solve psychological problems and help students form healthy psychology. The process of psychological consultation is actually a discussion process between psychological consultants and students. Psychological consultants are required to deeply ponder over students' problems, enlighten and encourage them, avoid giving comments and suggestions, guide students for autocriticism and self-cognition, rather than making students receiving their values, or else, students can easily generate dependence on psychological consultants, which goes against their healthy development.

\section{Conclusions}

In a word, psychological health status of current college students is unoptimistic. College students have many psychological problems in life and study. Their psychological health cannot be ensured only through psychological health courses. Psychological health consultation can optimize psychological health education network for college students. The base for psychological health education expands through training excellent students and making them participate in psychological consultation. Besides, the teaching force and effectiveness of psychological health education enhance. This has far-reaching influences on psychological health education of college students.

\section{References}

[1] Ministry of Education, Ministry of Health, The Central Committee of the Communist Young League, Opinions of Ministry of Education, Ministry of Health and The Central Committee of the Communist Young League on further enhancing and improving psychological health education of college students [Z]. JSZ[2005] No.1, 2005-1-12

[2] Chen Xi, Course of psychological health education of college students [M]. Beijing: Chemical Industry Press, 2007:3

[3] Liang Heng, Li Fazhan, Analysis of the causes of problems in psychological consultation and psychological health education of college students [J]. Social Sciences Review, 2008, (01):143

[4] Duan Xinxing, Zhao Ling, Psychological health education of college students [M]. Beijing: Science Press, 2004.28 